Contemporary Herpetology

ISSN 1094-2246

2000 Number 2

7 April 2000

\title{
CHARACTER ASSESSMENT, GENUS LEVEL BOUNDARIES, AND PHYLOGENETIC ANALYSES OF THE FAMILY RHACOPHORIDAE: A REVIEW AND PRESENT DAY STATUS
}

Jeffery A. Wilkinson (jwilkinson@calacademy.org) and Robert C. Drewes (kassina@.calacademy.org)

Department of Herpetology, California Academy of Sciences, Golden Gate Park, San Francisco, California 94118

Abstract. The first comprehensive phylogenetic analysis of the family Rhacophoridae was conducted by Liem (1970) scoring 81 species for 36 morphological characters. Channing (1989), in a reanalysis of Liem's study, produced a phylogenetic hypothesis different from that of Liem. We compared the two studies and produced a third phylogenetic hypothesis based on the same characters. We also present the synapomorphic characters from Liem that define the major clades and each genus within the family. Finally, we summarize intergeneric relationships within the family as hypothesized by other studies, and the family's current status as it relates to other ranoid families.

The family Rhacophoridae is comprised of over 200 species of Asian and African tree frogs that have been categorized into 10 genera and two subfamilies (Buergerinae and Rhacophorinae; Duellman, 1993). Buergerinae is a monotypic category that accommodates the relatively small genus Buergeria. The remaining genera, Aglyptodactylus, Boophis, Chirixalus, Chiromantis, Nyctixalus, Philautus, Polyp edates, Rhacophorus, and Theloderma, comprise Rhacophorinae (Channing, 1989). The family is part of the neobatrachian clade Ranoidea, which also includes the families Ranidae, Hyperoliidae, Dendrobatidae, Arthroleptidae, the genus Hemisus, and possibly the family Microhylidae. The Ranoidea clade is distinguished from other neobatrachians by the synapomorphic characters of completely fused epicoracoid cartilages, the medial end of the coracoid being wider than the lateral end, and the insertion of the semitendinosus tendon being dorsal to the $\mathrm{m}$. (musculus) gracilis (Ford and Cannatella, 1993). 
Liem (1970) analyzed the family Rhacophoridae along with some representatives of the family Hyperoliidae to revise the systematics and possibly construct a phylogenetic hypothesis of relationships among these families' genera. Based on this study, distinguishing characteristics of Rhacophoridae have been proposed as being: the fusion of carpals and tarsals; only one slip of the m. extensor digitorum communis longus inserting on the distal portion of the fourth metatarsal; the outermost slip of the $\mathrm{m}$. palmaris longus inserting on the proximolateral rim of the aponeurosis palmaris; the frontoparietal being trapezoidal; the terminal phalanx being bifurcate; and the presence of intercalary elements (if hyperoliids are not sister to rhacophorids, otherwise they share this characteristic; Channing, 1989; Ford and Cannatella, 1993).

Channing (1989), in a reanalysis of Liem's study and based on his set of characters, produced a cladogram in some respects similar to, but in many others different from Liem's preferred tree (Liem, 1970; Figure 1). The similarities are that the Malagasy rhacophorid genera and the genus Buergeria have basal positions, and Aglyptodactylus is sister to Mantidactylus. But, none of the remaining sister group relationships are common between the two topologies (e.g., Nyctixalus is sister to Theloderma in Channing's tree, but is sister to Chirixalus in Liem's tree) and Buergeria, not the (Mantidactylus, Aglyptodactylus) clade, is the most basal lineage. Based on this cladogram Channing proposed, as did Duellman and Trueb (1986), that rhacophorids and hyperoliids are sister groups, but he also moved the subfamily Mantellinae from Ranidae to Rhacophoridae because Mantidactylus (a mantelline ranid) and Aglyptodactylus (a rhacophorid) shared nine synapomorphies and were nested within the rhacophorid clade. The other mantelline genera Mantella and Laurentomantis were also moved to the family Rhacophoridae in his study (though no representatives of these genera were examined). Channing (1989) also proposed that the monotypic subfamily Buergeriinae be erected to accommodate the genus Buergeria, based not on any unique characters for this genus per se, but on its basal position in his tree (Figure 2).

Finally, Channing indicated that the subfamily Rhacophorinae (which in Frost [1985] includes the genera Aglyptodactylus, Boophis, Buergeria, Chirixalus, Chiromantis, Nyctixalus, Polyp edates, Rhacophorus, and Theloderma) is paraphyletic because in his reconstructed phylogenetic tree the genus Philautus, though considered the one genus of the subfamily Philautinae (Dubois, 1981; Frost, 1985), is nested well within the Rhacophorinae subfamily and is sister to Chiromantis (Figure 2), and because Aglyptodactylus forms a clade with Mantidactylus, as previously mentioned. Also, his most parsimonious trees support either Polypedates or the (Theloderma, Nyctixalus) clade being sister to the (Chirixalus, Chiromantis, Philautus, Rhacophorus ) clade, and within this clade, Rhacophorus is either sister to Chirixalus or the (Philautus, Chiromantis) clade.

As part of a larger project, we have re-analyzed the data set of Liem (1970) and its modification by Channing (1989) in an attempt to understand how different phylogenetic conclusions can result from the same characters, and to determine whether these 
characters are phylogenetically and taxonomically important in delimiting genera within this family. In other words, does each genus comprise a monophyletic group that can be separated from other genera by synapomorphic characters, based on the data set presented by Liem (1970)? We consider this important because the assignment of a species (particularly in Asia) before his study was based on the presence or absence of vomerine teeth, with species that contain vomerine teeth assigned to the genus Rhacophorus and those that lack vomerine teeth assigned to the genus Philautus (Inger, 1954, 1966; Taylor, 1962; Berry, 1975; Dutta and ManamendraArachchi, 1996). Yet, since the resurrection of the genera Buergeria, Chirixalus, and Polypedates (Liem, 1970), this method of species assignment appears to have been inadequate, resulting in numerous reassignments (Table 1).

\section{METHODS}

Liem (1970) provided an extensive data set of 112 character states for 36 morphological characters on 81 species that span most of the rhacophorid genera, and the results based on this data set have not been seriously challenged since his study. We performed phylogenetic analyses on the taxa selected by Liem for his analysis and using his original data set (Appendix 3 of Liem, 1970), and on the taxa selected by Channing using his modified data set (Table 2 of Channing, 1989) in order to compare state changes between the two studies. The phylogenetic analyses are based on cladistic methodology and maximum parsimony that are available in the program PAUP (Version 4.0b2; Swofford, 1999). In order to determine character polarization, we first constructed a hypothetical outgroup that contained all plesiomorphic states (as hypothesized by Liem, 1970). Character states were ordered following Liem's character descriptions and ordering diagrams. Though the polarities of these characters need to be tested with actual taxa as outgroup representatives, they were the assumptions used by Liem and Channing in their analyses and so will also be used here.

Secondly, we performed a phylogenetic analysis on all taxa from Liem's original data set (Appendix 3 of Liem, 1970), excluding species with identical character states as others of the same genus. Finally, if multiple species per genus were examined, then we chose one species at random to represent the genus and the analysis was performed. Subsequently, species were added to the analysis until either all species within the genus were included or multiple, most parsimonious trees were constructed. In this way, we could determine whether species of a designated genus formed a clade, and how each species operational taxonomic unit; (OTU) affected the analysis when added. Using the program MacClade (Version 3.04; Maddison and Maddison, 1992), we first analyzed synapomorphic characters of the major clades and then compared these to the characters for the genus descriptions given in Liem (1970). Finally, to determine the accuracy of the original character states, we examined many of Liem's characters on preserved, cleared and stained, and dry skeletal specimens of adult frogs for as many of the species included in the original study as were available to us, and on specimens of other congeners.

\section{RESULTS AND DISCUSSION}


Data analysis and phylogenetic reconstruction

Using Liem's taxa (Figure 56 of Liem, 1970), characters, states, and polarities (Appendix 3 of Liem, 1970) under a parsimony analysis resulted in 10 trees with a $\mathrm{Cl}$ (consistency index) of 0.524 , from which a strict consensus is given in Figure 3 . The consensus is similar to Liem's preferred tree (Figures 56, 60 of Liem, 1970; Figure 1) in that the Malagasy genera of Aglyptodactylus and Mantidactylus are most basal, and Polypedates forms a clade with Rhacophorus. It differs from Liem's preferred tree in that Buergeria is more basal than Boophis; Nyctixalus (Hazelia in Liem, 1970) forms a clade with Philautus instead of Chirixalus; and Chiromantis forms a clade with the (Polypedates, Rhacophorus) clade; and Chirixalus is sister to this clade. The relationships among Theloderma, the (Nyctixalus, Philautus) clade, and the (Chirixalus(Chiromantis(Polypedates, Rhacophorus))) clade could not be resolved.

Using Channing's choice of taxa for both the hyperoliids and rhacophorids but with Liem's original characters, states, and polarities produced 168 trees with a $\mathrm{Cl}$ of 0.462 (excluding the hyperoliid genera reduces the number of trees to 14). From the 168 trees, a strict consensus collapsed Chirixalus, Chiromantis, Philautus, Polypedates, Rhacophorus, and Theloderma into an unresolved polytomy (Figure 4). Again, as with Liem's preferred tree and the above consensus, Mantidactylus and Aglyptodactylus were most basal within rhacophorids, followed by Buergeria and then Boophis, before the polytomy. With Channing's modifications of Liem's characters, states, and polarities (Table 1 of Channing, 1989), these taxa produced nine trees with a $\mathrm{Cl}$ of 0.470 , from which the consensus was the same as Channing's tree (Figure 2). Three of the nine trees involved rearrangements of rhacophorid genera (as discussed above). Rhacophorus formed a clade with either Chirixalus or the (Chiromantis, Philautus) clade, with Chirixalus outside of this arrangement. Polypedates either formed a clade and was outside of the four taxa above or, if Rhacophorus formed a clade with the (Chiromantis, Philautus) clade, then Polypedates was outside of a clade with the four taxa plus a (Theloderma, Nyctixalus) clade. One of these three trees is also included in the 168 (14) trees resulting from Liem's characters, states, and polarities with Channing's choice of taxa, whereas the other two are one step longer.

The difference in the topologies can be attributed to the differences in both the representing taxa and the character states for each analysis. In the tree of Figure 3 and in Liem's preferred tree, Aglyptodactylus and Mantidactylus formed a clade that was basal to all other rhacophorid taxa, but in Channing's reanalysis Buergeria was more basal than the (Aglyptodactylus, Mantidactylus) clade. Because of this arrangement, he suggested that Mantidactylus be considered a rhacophorid genus instead of a ranid genus.

There are five conflicting characters $(1,6,14,16$, and 28$)$ that primarily influence the position of these taxa, and depending on whether or not hyperoliids are added to the analysis, have differing numbers of steps (Table 2). Characters 16 (state of the vertebral 
column) and 28 (presence or absence of a free third carpal) require fewer steps to evolve on the tree if Buergeria is basal to all other rhacophorids, whether hyperoliids are included or not (Figure 5). For the remaining three characters, the number of steps required differs according to whether or not hyperoliids are included. If only the rhacophorid genera are analyzed with a hypothetical ancestor to polarize the states (as Liem did) then the tree with the basal (Aglyptodactylus, Mantidactylus) clade is shorter by one step (Figure 6), and character 1 takes six steps and character 14 takes three steps to evolve on the tree. But if Buergeria is basal then both characters 1 and 14 take one step longer to evolve on the tree (Figure 7). If the hyperoliid taxa are included (as Channing did) then characters 1 and 14 take the same number of steps to evolve on the tree whether Buergeria or the (Aglyptodactylus, Mantidactylus) clade is basal (Figure 8). This is because Mantidactylus has the same state as the outgroup for both characters 1 and 14, but a more derived state is present in hyperoliids, causing the basal nodes to be equivocal for these two characters.

Channing recognized that Liem's ordering diagram for character 6 conflicts with the description in the text (pp. 22, 23 of Liem, 1970). He polarized character 6 based on Liem's description and not on his ordering diagram, and made state 1 the ancestral state. This makes the tree that includes the hyperoliids and in which Buergeria is basal to the other rhacophorids one step shorter than the tree in which the (Aglyptodactylus, Mantidactylus) clade is most basal to the other rhacophorids. If the hyperoliids are not included in the analysis, the tree having the (Aglyptodactylus, Mantidactylus) clade as the most basal clade is still shorter than the tree in which Buergeria is the most basal - even though character 6 takes one step more to evolve on the tree.

The phylogenetic position of Boophis among the other rhacophorid genera is constant whether hyperoliids are added to the analysis or not, in that it is the basal taxon of all rhacophorids except Aglyptodactylus, Mantidactylus, and Buergeria (Figure $2 \underline{2}$ and Figure 3 ). This position is primarily supported by character 4 , of which state 1 (the $\mathrm{m}$. adductor longus is absent) is present in all OTUs that form this clade (but is also present in the hyperoliid genus Leptopelis if hyperoliids are included; Figure 9). Characters 16 and 33 also support this clade but are considered to make reversals further within the clade. The clade excluding Boophis is strongly supported by characters 1 and 26, with state 3 of character 1 and state 1 of character 26 present in all OTUs of this clade exclusive of the other rhacophorids, though these states are also present in all of the hyperoliid genera (Figure 10). Characters 3 and 19 give weaker support to this node.

In Liem's preferred tree, the genus Nyctixalus was the sister taxon to Chirixalus. In Channing's reanalysis, Nyctixalus was the sister taxon to Theloderma. In the above reanalysis of Liem's taxa and character states, Nyctixalus formed a clade with Philautus. Liem based his support for the (Nyctixalus, Chirixalus) clade on the states (character/state) 1/2, 1/3, 3/2, and 16/1 (Figure 56 of Liem, 1970). The state 3/2 (a narrow $\mathrm{m}$. extensor radialis accessorius lateralis inserting on the distal tendon of the $\mathrm{m}$. extensor radialis superficialis) is the only state that may be a possible strong 
synapomorphy for this clade as it is only present in N. pictus, C. doriae, and $T$. stellatum among the species used by Liem in his analysis. The other three states are present throughout the rhacophorid taxa and not exclusive to these two genera.

Channing based his support for the sister group relationship of Nyctixalus and Theloderma on the character states 3/2, 8/2, and 12/0. As did Liem, Channing used $T$. stellatum to represent Theloderma, $C$. doriae to represent Chirixalus, and $N$. pictus to represent Nyctixalus, but used $P$. hosei instead of $P$. aurifasciatus and $P$. lissobrachius to represent Philautus. Again in Channing's analysis, the state $3 / 2$ is present in Nyctixalus, Theloderma, and Chirixalus, but not present in Philautus (state $3 / 1$ is present in $P$. hosei though $3 / 0$ is present in the remaining Philautus species scored by Liem). State $8 / 2$ (the $\mathrm{m}$. petrohyoideus posterior consisting of two slips, the anterior slip being 1 to 1.5 times wider than the posterior slip) is present only in Nyctixalus and Theloderma in Channing's analysis, and along with the state 3/2 would strongly support a construction with Nyctixalus and Theloderma as sister taxa. However, in the original data matrix of Liem (Appendix 3 of Liem, 1970), T. stellatum is scored as having state $8 / 0$, not $8 / 2$ as in Channing's data matrix (Table 1 of Channing, 1989). Because Channing based his analysis on Liem's data matrix, this must be a mistake on his part. Instead, state $8 / 2$ is present in most of the species of Philautus scored by Liem (except $P$. hosel) and thus becomes a strong synapomorphy for Nyctixalus being a sister taxon to Philautus as discussed below.

Two additional surprising results of Channing's reanalysis, were that Chiromantis and Philautus were sister taxa, but Rhacophorus and Polypedates were not (Figure 2). Again, these results can be attributed to the choice of species to represent each genus. Channing chose $R$. microtympanum to represent Rhacophorus, $P$. dugritei to represent Polypedates, $C$. xerampelina to represent Chiromantis, and, as discussed above, $P$. hosei to represent Philautus.

The character states $16 / 0$ and 19/1 support Chiromantis and Philautus as sister taxa in Channing's reanalysis, with 19/1 (anterior portion of the frontoparietal being wider than the posterior portion) being present only in this clade, thus giving the strongest support (Figure 11). However, all species of Philautus scored by Liem except for $P$. hosei have the state 19/5 (frontoparietal is trapezoidal, the parieto-squamosal arch is absent); also most of the species of Rhacophorus (but not $R$. microtympanum) and some of the species of Polypedates scored by Liem have the state 19/1. Liem also stated that along with $R$. appendiculatus and $R$. everetti, $R$. microtympanum differs from other members of Rhacophorus in many characters and is only provisionally placed in this genus until further study can be done (pg. 99, 100 of Liem, 1970). Therefore, it may be that these species ( $P$. hosei and $R$. microtympanum) do not belong to or misrepresent their respective genera in Channing's analysis. In addition to this, Channing probably misscored character 11 for Rhacophorus, since there are only two possible states ( 0 and 1 ) but Rhacophorus is given state 2 in his analysis (Table 2 of Channing, 1989). In this case, if Rhacophorus is given the state of 1 , then the resulting nine cladograms are the same as those of Channing (1989); but if Rhacophorus is given the state of 0 (this is the 
state for R. microtympanum in Appendix 3 of Liem, 1970) then the resulting three cladograms have Rhacophorus forming a clade with the (Chiromantis, Philautus) clade.

Analysis with remaining taxa

For the present analysis, eleven of the 81 species analyzed by Liem were removed from the data set because they had exactly the same character states as other congeners and would only elevate the number of most parsimonious trees. Performing a parsimony analysis on the remaining 70 OTUs resulted in the program terminating before completion. Analyzing the rhacophorid taxa separately from the hyperoliid taxa still resulted in the program terminating before completion. However, by removing two rhacophorid species (Rhacophorus appendiculatus and $R$. microtympanum) and analyzing only the 48 remaining rhacophorid taxa resulted in 118 most parsimonious trees with a $\mathrm{Cl}$ of 0.337 , a strict consensus of which is presented in Figure 12. In this consensus tree, the taxa in the genera Theloderma and Nyctixalus are unresolved forming a polytomy with a large, relatively resolved clade of Chiromantis, Polypedates, and Rhacophorus, and a clade containing most of the species of Chirixalus. We then performed a parsimony analysis using Liem's original character states and polarizations on as many OTUs as possible in order to construct a resolved or near resolved cladogram(s). Our objective was to distinguish genera with multiple representatives from other such genera by characters or sets of characters, and better understand the relationships of species traditionally assigned to a certain genus but that are at odds with other members of that genus according to these characters.

One parsimony analysis performed on 38 OTUs (38 of the 48 species in Figure 12) for all 11 rhacophorid genera in Liem's data set resulted in six most parsimonious trees with a $\mathrm{Cl}$ of 0.417 , in which no polytomies among the genera would form when performing a strict consensus. Including any one or a combination of the 12 excluded species would not increase resolution but only create polytomies as discussed below. In these trees, the genera Mantidactylus and Aglyptodactylus formed a clade that was basal to the remaining rhacophorid genera. This was followed by the genus Buergeria, then Boophis, and then Theloderma. After Theloderma, there were two clades, one with Philautus and Nyctixalus as sister genera, and a larger clade with Chirixalus as the most basal genus, followed by Chiromantis, then Polypedates and Rhacophorus as sister genera (Figure 13). Another parsimony analysis that included 18 additional OTUs from all of the hyperoliid genera (for a total of 56 OTUs), in which the polarity of character 6 was changed to reflect Liem's text description, produced 30 most parsimonious trees with a $\mathrm{Cl}$ of 0.360 . The strict consensus of these has the same topology for the rhacophorids as in Figure 13, except that Buergeria is now the most basal genus of the rhacophorids (Figure 14). A bootstrap analysis of 10,000 reiterations (under the fast-hueristic approach in PAUP) indicated weak support for nodes that grouped genera into major clades (Figure 14). This is because of the limited number of non-homoplastic synapomorphic character states at these nodes.

Support for the major clades and a discussion of the genera 
Based on the resulting most parsimonious trees from the analysis above (Figure 14), and following the ordering of character states given by Liem (1970), the major clades within the family Rhacophoridae plus their synapomorphies are discussed below. The original character state definitions are given in Liem (1970) and will only be mentioned as synapomorphies for specific clades here. The synapomorphic characters for each clade should distinguish all members of that clade from all other taxa, unless stated otherwise. In Liem's original study, the genera Buergeria, Chirixalus, and Polypedates were resurrected and, along with the other genera, given diagnoses and definitions to distinguish each from the other genera of rhacophorids. A comparison of these character descriptions with those based on the phylogenetic hypothesis above are presented. Our designations may differ from Liem's because the characters will be used as synapomorphies that describe monophyletic groups in an hierarchical order following the concept of phylogenetic taxonomy (de Queiroz and Gauthier, 1992). Within this context, the synapomorphic characters that diagnose a monophyletic group may not be present in all taxa of that group, and some synapomorphies may be homoplastic by reversing within the group or occurring as synapomorphies that also diagnose other groups.

The clade of Rhacophoridae and Hyperoliidae

The following character states support this clade in our analysis:

1. The m. humerodorsalis splits into two main halves: The medial half consists of two distal slips, the lateral half consists of the fourth phalangeal and fourth metacarpal slips (1/1). This state is scored as being present only in the taxa Buergeria and Boophis, and Rhacophorus moltrechti; reverses to state 0 in Aglyptodactylus and Mantidactylus, and is the more derived state 3 in the remainder of the rhacophorids and hyperoliids. This character leading to the node is equivocal for states 0 and 1 (Figure 15).

2. Only one slip of the $m$. extensor digitorum communis longus inserts on the distal portion of the fourth metatarsal (5/1). States 0,1 , and 2 are present in rhacophorids (discussed below), while states 3 and 4 are expressed in hyperoliids (igure 16).

3. The anterior horn of the hyoid consists of two processes: a median and a lateral branch (14/1). This character state could only be scored if the anterior horn was present $(13 / 0)$, therefore it was not scored for the rhacophorid genera

of Nyctixalus, Polypedates, Rhacophorus (except $R$. everetti), and Theloderma and the hyperoliid genus Kassinula. This state either continued to the more derived state 2 (Buergeria and Leptopelis) or reversed to state 0 (see Mantidactylus, Chirixalus, Phlyctimantis, Hyperolius, and Kassina) further within the clade (Figure 17).

4. The contour of the centrum viewed ventrally is only slightly cylindrical $(17 / 1)$. This character state continues to state 2 (Mantidactylus, Nyctixalus, Philautus), and reverses to state 0 (Chirixalus, Chiromantis, Polypedates, and Rhacophorus) further within the 
rhacophorid clade, but is constant in the hyperoliid clade except for two species of Leptopelis where it reverses back to state 0 (Figure 18) $<\mathrm{p}<$ $\mathrm{p}=" "></ \mathrm{p}<>$

5. The terminal segment of each digit is extensively dilated, with a rounded pad that is surrounded distally and laterally by a ventro-marginal groove. No transverse groove is present (33/2). This state is seen extensively within hyperoliids but changes to more derived states $(33 / 3,4)$ in rhacophorids as discussed below (Figure 19).

As discussed above and in Ford and Cannatella (1993), this clade has yet to be determined based on comparisons with other ranoid taxa (but see below).

Rhacophoridae

In our analysis, the family Rhacophoridae includes the genera Aglyptodactylus, Boophis, Buergeria, Chirixalus, Chiromantis, Mantidactylus, Ny ctixalus, Philautus, Polypedates, Rhacophorus, and Theloderma. There are eight character state changes at the node leading to the rhacophorids, as follows:

1. The outermost slip of the m. palmaris longus inserts on the proximolateral rim of the aponeurosis palmaris (2/2). Except

for Aglyptodactylus madagascariensis and Mantidactylus ulcerosus, all rhacophorid taxa in the analysis have either state 2 or state 3 (as discussed below) which is considered to have been derived from 2 (Figure 20).

2. The frontoparietal is trapezoidal (19/5). This state is present in the basal taxa but reverses further within the rhacophorid clade, as discussed below (Figure 21).

3. The nasals are squash- shaped and not in contact with each other, but are usually in contact with the sphenethmoid (20/3). The state for this character is equivocal leading to the node for rhacophorids because of its presence in the basal hyperoliid genus Leptopelis. The more derived state 4 is present in Aglyptodactylus, Mantidactylus and Philautus (Figure 22).

4. The metasternum is a narrow bony stylus (25/0). Liem argues that the outgroup should possess a broad cartilaginous metasternum because it is a common character in non-ranoid frogs and in a few ranid frogs. Channing disagrees with Liem and assumes the outgroup to have a bony metasternum. Either way, state 0 is consistent throughout rhacophorids, and the other state is constant throughout hyperoliids (Figure 23). Whether it is derived or primitive will therefore depend on how it is scored at the outgroup node (discussed below).

5. The terminal phalanx is bifurcate (27/2). This state also defines a clade within hyperoliids, and reverses within Aglyptodactylus and Philautus. A more derived state defines a clade further within rhacophorids, as discussed below (Figure 24). 
6. The third carpal is fused to the fourth and fifth carpals (28/1). This state is equivocal at the rhacophorid node because, though the third carpal is fused in most of the rhacophorids, it is considered free in Aglyptodactylus and Mantidactylus (but see below), all hyperoliids, and the outgroup (Figure 25). Again, the interpretation of the outgroup state is in contention. Whereas Liem (1970) and Channing (1989) consider the outgroup condition to be a free third carpal, Drewes (1984) contends that the free third carpal is a synapomorphy for all hyperoliid taxa, and is independently present in a few ranid taxa. Ford and Cannatella (1993) agree that the polarity is incorrect because the fusion of the third carpal is widespread in ranids.

7. The second tarsal is fused to the third and fourth tarsals (29/1). As with the above character, the outgroup condition of this character is in contention. All rhacophorid taxa in the analysis except for Boophis tephraeomystax have a fused second tarsal (Figure 26; but see below).

8. The terminal segment of the digit is extensively dilated, the pad is surrounded distally and laterally by a ventro-marginal groove, and a transverse groove runs across the proximal portion of the pad (33/3). This state and the more derived state 4 are exclusive to the rhacophorid taxa (Figure 19).

Besides the above, Ford and Cannatella (1993) stated that the presence of intercalary elements (not in analysis) may be a synapomorphy for this clade if hyperoliids are not considered the sister family to rhacophorids (Figure 27); otherwise it is a synapomorphy for the (Hyperoliidae, Rhacophoridae) clade above.

\section{Buergeria}

This genus was represented by the species $B$. japonica, B. pollicaris, and $B$. robusta in the present analysis. This genus is considered the most basal group of rhacophorids according to the analysis above. It possesses the eight character states attributed to the family Rhacophoridae as discussed above. Though there are no characters unique to the clade, it can be distinguished from other genera of rhacophorids by a combination of the following synapomorphic characters.

1. The small medial slip of the lateral half of the $m$. palmaris longus is absent $(2 / 3)$. This character state is also a synapomorphy for the clade of Chirixalus, Chiromantis, Polypedates, and Rhacophorus, and is expressed in some species of Philautus (Figure 20).

2. One slip of the $\mathrm{m}$. extensor digitorum communis longus is present, inserting on the distal portion of the metatarsal of the fourth toe (5/2). This character state is considered to be derived from state 1, which defines the (Rhacophoridae, Hyperoliidae) clade. It is also a synapomorphy for a more exclusive clade further within the rhacophorid clade (Figure 16). 
3. Only the median branch of the anterior horn of the hyoid is present (14/2). This character state is also scored as being present in all species of the genus Leptopelis sampled by Liem (1970), and in the species Philautus woodi, Rhacophorus appendiculatus, $R$. everetti, and $R$. microtympanum (only P. woodi was included in analysis; Figure 17).

Within Rhacophoridae, the genus Buergeria was again erected by Liem (1970) to accommodate the three or four species that are endemic to islands bordering the Asiatic coast. These species are B. buergeri of Honshu, Kyushu, and Shikoku, Japan; $B$. japonica of Taiwan and the Ryukyu Archipelago; B. robusta of Taiwan; and possibly $B$. oxycephalus (Rhacophorus oxycephalus in Frost, 1985) of Hainan Island. Though $B$. pollicaris of Taiwan was used in Liem's analysis it was probably a variant of $B$. japonica or $B$. robusta, as no $B$. pollicaris species is presently considered to inhabit Taiwan (Lue and Lai, 1990). These species are considered "primitive" rhacophorids in both Liem's original work and Channing's re-analysis. Liem stated (pg. 67, 1970) that a combination of the following character states define this genus: (1) the presence of the second and fourth phalangeal slips of the m. humerodorsalis (1/1), however, this character state actually defines a more inclusive clade; (2) the presence of the $M$. adductor longus (4/0), however the absence of this muscle (4/1) defines the clade from which Buergeria is excluded, and the state here is considered symplesiomorphic by being present in the (Aglyptodactylus, Mantidactylus) clade and the outgroup; (3) an arch-shaped anterior horn of the hyoid (14/0), this definition is a mistake as he scores all OTUs in this clade with a state of 2 and later states that only the medial branch of the anterior horn of the hyoid is present (pg. 90,1970). Of the three character states, only the last state (if defined correctly) is also used in the present analysis as a character to define this genus.

The clade of Aglyptodactylus, Boophis, Chirixalus, Chiromantis, Mantidactylus, Nyctixalus, Philaut us, Polypedates, Rhacophorus, and Theloderma

Support for this clade as discussed above is provided by the following character states:

1. The $\mathrm{m}$. dentomentalis is fan-shaped; the m. submaxillaris ventralis and the $\mathrm{m}$. submaxillaris are distinct (6/0). This state reverses further within the clade to define the genus Chirixalus, and is present in some subclades of Chiromantis, Rhacophorus, and Polypedates as discussed below (Figure 28).

2. The vertebrae are procoelous (16/1). This character state reverses further within the clade to define the clade for Chiromantis, Polypedates, and Rhacophorus as discussed below (Figure 29).

The clade of Aglyptodactylus and Mantidactylus

This clade is supported by six characters: 
1. The $\mathrm{m}$. humerodorsalis splits into three slips (1/0). This state, though unique for rhacophorids, is also in the outgroup. Thus it is considered a reversal to the ancestral condition (Figure 15).

2. The anterior horn of the hyoid consists of a complete arch (14/0). This state is apparently independently present in the outgroup, the hyperoliid species Kassina (Hylambates in Liem) maculatus, and the genus Chirixalus (Figure 17; see below).

3. The segment of neuropophysis connecting the centrum and the transverse process of the eighth vertebrae attaches on the ventro-lateral portion of the centrum. Thus the contour of the centrum when viewed ventrally is not cylindrical (17/2). This state is also present in all OTUs of the (Nyctixalus, Philautus) clade and was not scored in $A$. madagascariensis, as discussed below (Figure 18).

4. The nasals are club shaped and are usually in contact with the sphenethmoid, which is large with an exposure of 0.6 to 1.0 times the length of the frontoparietal (20/4). This state is also present in species of the genus Philautus (Figure 22).

5. The first, second, and third carpals are free (28/0). As discussed above, this character state is present in all hyperoliid taxa and is considered the outgroup state. Because Buergeria is considered the basal taxon, the state of this character to this node is equivocal (Figure 25).

6. The two outer metatarsals are united or are separated by only a groove (32/1). This character state is also in all OTUs of the genus Philautus and the family Hyperoliidae (Figure 30).

\section{Aglyptodactylus}

This monotypic genus (but see Glaw et al., 1998) is represented by the species $A$. madagascariensis in the analysis. It can be distinguished from other rhacophorids by the above six characters that are synapomorphies for the (Aglyptodactylus, Mantidactylus) clade, and from species of Mantidactylus by the following two characters though Liem discusses this genus as a part of Mantidactylus (see below):

1. The small medial slip of the lateral half of the $\mathrm{m}$. palmaris longus is absent (2/4). This state is also present in Philautis hosei (not in analysis; Figure 20).

2. The terminal phalanx is obtuse (27/1). This state is unique to this genus among all other rhacophorid OTUs, but is also present in most of the hyperoliid species (Figure 24).

\section{Mantidactylus}


For this genus of over 50 species, the three species $M$. albofrenatus, $M$. luteus, and $M$. ulcerosis were used in the analysis. Aglyptodactylus madagascariensis formed a clade with $M$. albofrenatus and $M$. ulcerosis exclusive of $M$. luteus in the analysis, making this genus paraphyletic with the present data set. Liem did not recognize Aglyptodactylus as separate from Mantidactylus, and the synapomorphic character states of the (Aglyptodactylus, Mantidactylus) clade were discussed above.

Liem characterizes this clade by four characters: the $\mathrm{m}$. humerodorsalis splitting into three main slips (1/0); an incompletely divided $\mathrm{m}$. palmaris longus (2/1); vomerine odontophore usually in contact with palatine bone; and femoral glands present in many species. He states that the last three characters are unique to this clade (pg. 66, 1970). The $\mathrm{m}$. humerodorsalis splitting into three main slips $(1 / 0)$ is present only in this clade among the other rhacophorid genera, but since it is also considered to be in the outgroup, it is a symplesiomorphic character state that does not characterize this clade in the cladogram. Though he states that the species of this clade have state 1 of character 2 (pg. 66 of Liem, 1970), he scores all OTUs of this clade with the states 0, 2, and 4 but not 1 (Appendix 3 of Liem, 1970). He may have made a mistake here. All three of these states are present either in other OTUs of the ingroup, or in the outgroup. Liem did not use the last two characters in his analysis. He also stated that the third carpal is free and usually the second tarsal is free (pg. 87 of Liem, 1970) but he scored only the third carpal as being free (28/0). As with state 0 of character 1 , this state (28/0) is not considered an apomorphy for this clade because it is also present in the outgroup. It does, however, separate this clade from the remaining rhacophorid OTUs (but see below).

The clade of Boophis, Chirixalus, Chiromantis, Nyctixalus, Philautus, Polypedates, Rhacophorus, and Theloderma

The support for this clade is provided by the following five characters:

1. The $\mathrm{m}$. adductor longus is absent (4/1). This state is unique to this clade among all rhacophorid OTUs in the analysis (Figure 31). However, this character state is also scored the same in all species of Leptopelis sampled by Liem and scored differently in the species Boophis bicalcaratus (not used in analysis).

2. The alary process of the hyoid is club shaped (12/1). Other than this state reversing in Nyctixalus pictus and Polypedates dennysi, it is present in all OTUs of the clade or changes to the more derived state 2 further within the clade (Figure 32).

3. The base of the omosternum is slightly forked (24/1). As above, other than this state reversing at the node for Philautus or in Chiromantis rufescens, it is present in all OTUs of the clade or changes to the more derived state 2 further within the clade (Figure 33).

4. The third carpal is fused (28/1). Except for members of the (Aglyptodactylus, Mantidactylus) clade this state is the same for all rhacophorids, 
therefore it is equivocal up to this node because of the position of the (Aglyptodactylus, Mantidactylus) clade (Figure 25).

5. The terminal segment of the digit is extensively dilated; the digital pad is oval and oriented transversely across the digital disc; the digital pad is completely surrounded by a deep groove, of which the posterior portion is the transverse groove and the remaining portion is the ventro-marginal groove (33/4). This state is also present in Buergeria japonica and reverses at the node to the clade that defines Chiromantis (Figure 19).

\section{Boophis}

This genus contains approximately 28 species and was represented by the species $B$. tephraeomystax in the analysis. It can be distinguished from other rhacophorids by a combination of the following synapomorphic character states:

1. The anterior horn of the hyoid is absent (13/1). This state is also present in Nyctixalus pictus and defines the (Polypedates, Rhacophorus) clade (see below), but is not found in $B$. bicalcaratus (Figure 34).

2. The base of the omosternum is moderately forked (24/2). This state is also independently present in Chiromantis petersi, Polypedates leucomystax, and three Rhacophorus species. State 3 is present in B. bicalcaratus (Figure 33).

3. The second tarsal is free (29/0). This state is unique within the rhacophorid OTUs, though it is present throughout hyperoliids and is considered the state for the outgroup (but see below). It is also scored as being present in $R$. appendiculatus (not used in analysis) but not in B. bicalcaratus (Figure 26).

Liem distinguished this genus from other rhacophorids by a ranid type $m$. humerodorsalis (1/0), though he scored the two species with states $1 / 1$ and $1 / 3$; the presence of an $\mathrm{m}$. adductor longus (4/0) (this is actually scored as being absent in $B$. tephraeomystax), reduced nasal bones (this state is not designated, but state $20 / 3$ is scored in $B$. tephraeomystax while state $20 / 2$ is scored in B. bicalcaratus), and the presence of two $\mathrm{m}$. extensor digitorum communis longus slips (5/1), though this is not a unique character of Boophis and is scored as 5/2 in B. bicalcaratus.

When $B$. bicalcaratus was included in the analysis, either alone or with $B$. tephraeomystax, it would collapse Theloderma, the (Nyctixalus, Philautus) clade, and the (Chirixalus(Chiromantis(Polypedates, Rhacophorus))) clade into a polytomy. The species $B$. bicalcaratus differs from $B$. tephraeomystax at nine characters, including the three characters above. It is also interesting to note that $B$. bicalcaratus is not a recognized species in recent texts, instead, Mantidactylus bicalcaratus is known from Madagascar (Frost, 1985; Glaw and Vences, 1992), indicating that Liem may have used an individual of questionable taxonomic status. Because Boophis is a relatively large genus restricted to Madagascar, but $B$. tephraeomystax and $B$. bicalcaratus differed so 
extensively in the analysis, further analysis with more species is probably required to determine whether the above synapomorphies actually support the monophyly of this genus.

The clade of Chirixalus, Chiromantis, Nyctixalus, Philautus, Polypedates, Rhacophorus, and Theloderma

Support for this clade is provided by two characters:

1. The $\mathrm{m}$. humerodorsalis is completely divided, inserting on the third and fourth metacarpals (1/3). This character state reverses in $R$. moltrechti, but otherwise is the same in all OTUs of this clade. It is also present throughout all hyperoliid taxa, and is thus a synapomorphy for that clade (Figure 15).

2. The distal end of the third metacarpal is distinctly dilated distally and a prominent disto-medial bony knob is present (26/1). This character state (Figure 35) is present throughout all OTUs of this clade and therefore is the strongest support for this node, though it is also present in all hyperoliid taxa (Figure 36).

\section{Theloderma}

This genus contains approximately 10 species and was represented by $T$. gordoni in the analysis. There is no character state from the data set that provides a synapomorphy for this lineage, yet as many as seven characters were not scored.

Liem stated that a combination of the following character states distinguishes this genus from other rhacophorids: two m. extensor digitorum communis longus slips (5/1) (yet this state is also present in Boophis tephraeomystax and Mantidactylus luteus, and the state 5/2 defines a more exclusive clade, as discussed below); and numerous calcified warts on the dorsum (not used in the analysis). Based on breeding behavior (laying small clutches of eggs above water- filled holes in tree trunks), Liem suggested that Theloderma may be closely related to Nyctixalus, as was the result of Channing's analysis. Yet, species of Philautus and Chirixalus (C. eiffingeri) also have the same breeding behavior.

When Theloderma stellatum was added to the analysis, instead of forming a clade with T. gordoni it instead formed a polytomy with the (Nyctixalus, Philautus) clade and the (Chirixalus (Chiromantis (Polypedates, Rhacophorus))) clade. If $T$. stellatum alone represents Theloderma in the analysis then the (Chirixalus (Chiromantis (Polypedates, Rhacophorus))) clade collapses into a polytomy with it and the (Nyctixalus, Philautus) clade.

The clade of Chirixalus, Chiromantis, Nyctixalus, Philautus, Polypedates, and Rhacophorus 
This clade is weakly supported by state 2 of character 5 ; one slip of the $\mathrm{m}$. extensor digitorum communis longus is present, inserting on the distal portion of the metatarsal of the fourth toe (absent in Theloderma gordoni but present in T. stellatum), in that this character reverses further within the clade and also occurs in Buergeria, Aglyptodactylus and some species of Mantidactylus (Figure 16).

The clade of Nyctixalus and Philautus

The clade with these two genera as sister taxa is supported by four characters.

1. The $\mathrm{m}$. petrohyoideus posterior consists of two slips, with the anterior slip being 1 to 1.5 times the width of the posterior one (8/2). This character state is unique to this clade and therefore provides the strongest support, though it reverses in $P$. nasutus (Figure 37).

2. The segment of neuropophysis connecting the centrum and the transverse process of the eighth vertebrae attaches on the ventro-lateral portion of the centrum (17/2). This state is present in all OTUs of this clade but is also present in all OTUs of the (Aglyptodactylus, Mantidactylus) clade (Figure 18).

3. The Wolffian duct along the kidney is a simple tube (30/0). This state, though present in all OTUs of this clade, is equivocal at this node, and is present in basal rhacophorids, most hyperoliids, and the outgroup. Thus it is only a weak support for this clade (Figure 38).

4. A bottle-shaped vesicula seminalis is present (31/1). This state is present in all OTUs of this clade but is also present in Chiromantis xerampelina (Figure 39).

\section{Nyctixalus}

This genus contains only two or three species and was represented by N. pictus in the analysis. It is considered a sister taxon to Philautus in the analysis (as discussed above), it possesses all of the character states of the above clades, plus it can be distinguished from members of Philautus by a combination of the following characters:

1. The alary process of the hyoid is dilated distally $(12 / 3)$. This character state is also present in all hyperoliids except Leptopelis (Figure 32).

2. The anterior horn of the hyoid is absent (13/1). This state is also present in $B$. tephraeomystax and all OTUs of the (Polypedates, Rhacophorus) clade (Figure 34; see below).

3. The frontoparietal is rectangular, and the parieto-squamosal arch is absent (19/0). This state is also in the outgroup, hyperoliids, Chirixalus, and $P$. dugretii, and it is equivocal leading to the node that splits Nyctixalus from Philautus (Figure 21). 
Liem characterized this genus by the following combination of characters: warty dorsum, head skin co-ossified to the skull, the presence of bony ridges along the frontoparietals, lack of vomerine teeth, and a median anal opening in the tadpoles (p. 69 of Liem, 1970), with the third and fifth of these characters being unique. Except for the presence or absence of vomerine teeth, none of these characters were used in the analysis. He also stated (p. 96 of Liem, 1970) that the vomerine teeth are absent and the terminal phalanges are $\mathrm{Y}$-shaped (though he codes these characters differently in the analysis); that the anterior horn of the hyoid is absent (discussed as a character above); that the vertebral column is procoelous and moderately long and the nasals are squash-shaped (not scored as a characteristic of this genus in his analysis); that the m. extensor radialis accessorius lateralis is very slender and originating from the crista ventralis of the humerus (this state is throughout the rhacophorid OTUs and thus highly homoplastic), that the $\mathrm{m}$. humerodorsalis consists of two completely separated slips, the $\mathrm{m}$. adductor longus is absent, and the omosternum is only slightly forked at the base (synapomorphies of a more inclusive clade), and that only two slips of the $\mathrm{m}$. petrohyoideus posterior is present and convoluted Wolffian ducts are absent (characters for the more inclusive clade of (Nyctixalus, Philautus) as discussed above).

\section{Philautus}

Presently, this genus contains approximately 80 species, from which the species $P$. acutirostris, $P$. aurifasciatus, $P$. emembranatus (= P. worcesteri; Brown et al., 1998), $P$. lissobrachius, $P$. nasutus, $P$. parvulus, $P$. surdus, and $P$. woodi were used in the analysis. As a member of more inclusive rhacophorid clades, members of this genus possess the same character states for these clades as mentioned above except where noted here. This genus can be distinguished from its sister genus, Nyctixalus, by a combination of the following synapomorphic character states:

1. The $\mathrm{m}$. extensor radialis accessorius lateralis is moderately large, the width at the origin being 0.75 to 1.5 that of the $\mathrm{m}$. extensor radialis superficialis, and it originates along the lateral side of the humerus (3/0). This character state is equivocal at the node and is present in more basal rhacophorids, all hyperoliids, and the outgroup (Figure 40).

2. The alary process is blade-shaped, with or without slight dilation at the distal end (12/2). This character state is present in all OTUs of the clade, but it is also a synapomorphy for a clade of Rhacophorus and Polypedates species as discussed below (Figure 32).

3. The relative length of the vertebral column is from 1.6 to $2.4(18 / 1)$. This character state is unique to and present in all OTUs of the clade, thus it is the strongest support for this genus (Figure 41).

4. The frontoparietal is trapezoidal, and the parieto-squamosal arch is absent (19/5). This character state is equivocal at the node to this genus and is also present in basal rhacophorids and some hyperoliids (Figure 21). 
5. The vomerine teeth are either present or absent in at least 25 percent of the samples examined (22/1), or the vomerine teeth are always absent (22/2). These two states also occur in some species of hyperoliids and the genera Buergeria, Rhacophorus, and Polypedates (Figure 42)

6. The base of the omosternum is not forked (24/0) and the nuptial pad is absent (35/1). Both of these characters show similar patterns with respect to Philautus in that the states reverse in $P$. parvulus and are present in other non-sister taxa (Figure $\underline{33}$ and Figure 43).

7. The two outer metatarsals are united, or are separated only by a groove (32/1). This character state is also in all OTUs of Aglyptodactylus and Mantidactylus , the family Hyperoliidae, and $P$. hosei (not in analysis; Figure 30).

Liem distinguishes this genus based on the following characters: trapezoidal frontoparietal (same as above); unique broad neuropophyses of the eight vertebra; two m. petrohyoideus posterior slips; simple Wolffian duct; and distinct vesicula seminalis (all are characteristic of the more inclusive group with Nyctixalus as stated above); and extremely large eggs of gravid females (not used in analysis).

The species $P$. schmackeri was not included in the analysis because it possessed character states identical with $P$. aurifasciatus and therefore would only be redundant (but otherwise is considered part of the genus Philautus). The species $P$. hosei and $P$. leucorphinus were not included in the analysis because of their effects on producing a single most parsimonious cladogram. If $P$. leucorphinus were included, then a polytomy would form among the (Chirixalus(Chiromantis(Polypedates, Rhacophorus))) clade, Nyctixalus, Theloderma, and Philautus, even though P. leucorphinus would be within the Philautus clade. If $P$. hosei were included, then a polytomy would form between most species of the Chirixalus, Chiromantis, Nyctixalus, Philautus, Polypedates, Rhacophorus, and Theloderma clade. In fact, even though $P$. leucorphinus possessed the same states as listed above for Philautus, $P$. hosei was scored differently from all of the other species of Philautus in Liem's data set at four of the eight characters listed above. The large number of species in the genus and the constant reassignments of species to and from this genus require that it be analyzed more rigorously. As a starting point, the character states above can be tested as those for including species within this genus.

The clade of Chirixalus, Chiromantis, Polypedates, and Rhacophorus

This clade is supported by the following characters:

1. The small medial half of the $m$. palmaris longus is absent $(2 / 3)$. This state is also present in Buergeria and reverses to state 2 in some Rhacophorus species (Figure 20). 
2. The contour of the centrum of the eighth vertebrae is cylindrical $(17 / 0)$. This state is unique within rhacophorids but is also in the outgroup and some species of Leptopelis, and reverses in two of the OTUs within the clade (igure 18).

3. The frontoparietal is rectangular, and the parieto-squamosal arch is absent (19/0). This character state is also present in the outgroup and the hyperoliids, further within the clade this state changes to more derived states as discussed below (Figure 21).

\section{Chirixalus}

This genus consists of approximately eight species. In the present analysis, this genus is represented by the two species $C$. doriae and $C$. hansenae. In addition to possessing the synapomorphic character states mentioned for the more inclusive clades above, this genus also possesses the following synapomorphic character states:

1. The $\mathrm{m}$. dentomentalis is fan shaped and distinct; the $\mathrm{m}$. submaxilaris ventralis is not distinct from the $\mathrm{m}$. submaxillaris; and they form a continuous muscle layer (6/1). This character state is also present in Buergeria, and some species of Chiromantis, Polypedates, and Rhacophorus (Figure 28).

2. The alary process is absent (11/1). This character state is also similarly scored in $P$. omeimontis but in all other rhacophorids and hyperoliids the alary process is present (Figure 44).

3. The anterior horn of the hyoid consists of a complete arch along the anterior portion of the hyalia (14/0). This state is also present in Mantidactylus, the outgroup, and some hyperoliids (Figure 17).

4. The relative length of the vertebral column is more than 2.4 times (18/2). This character state is unique to rhacophorids but also supports a clade within hyperoliids (Figure 41).

Liem erected and distinguished this genus from other rhacophorids based on a combination of the following characters: the vertebral column is elongated (same state as 18/2 above), vomerine teeth usually absent (this state is scattered throughout most rhacophorids), and opposable fingers (not used in analysis).

Of the five species examined by Liem, $C$. vittatus is externally very similar to $C$. doriae, and in the analysis differed from $C$. doriae and $C$. hansenae at five characters, one of which was character 6 above. Yet, the inclusion of $C$. vittatus collapsed the Chirixalus node to a polytomy with the (Nyctixalus, Philautus) and the (Chiromantis (Polypedates, Rhacophorus)) clades. Therefore, a re-examination of the character states of $C$. vittatus appears to be warranted. Of the remaining two species in Liem's data matrix, C. nongkhorensis differed from the above two OTUs at 10 characters, with only character 11 from the above four having the same state, and $C$. eiffingeri differed from the above two OTUs at 12 characters, with none of the above 
characters having the same state. In addition to this, though the presence of an anterior horn of the hyoid (13/0) is scored in Liem (1970) for C. eiffingeri, we have found it to be absent in specimens we looked at (CAS 24444, CAS 24492; Figure 45). Also, opposable digits, which are considered a diagnostic character for Chirixalus (Taylor, 1962), and which are present in $C$. doriae and $C$. vittatus are not present in $C$. eiffingeri (Figure 46). Finally, foam nesting as a characteristic of the genus Chirixalus (Duellman and Trueb, 1986; Jiang et al., 1987; Liem, 1970), is absent in C. eiffingeri, which instead deposit eggs in tree holes or bamboo stalks (Lue and Lai, 1990; Maeda and Matsui, 1990; personal observation). Therefore the inclusion of these two species within Chirixalus, especially $C$. eiffingeri, may be questionable (Maeda and Matsui, 1990).

The clade of Chiromantis, Polypedates, and Rhacophorus

This clade is supported by the following characters:

1. The $m$. extensor radialis accessorius lateralis inserts on the distodorsal end of the radio-ulna (3/1). This character is equivocal at the node with Chirixalus, though unique to this clade, reversing further within the clade (Figure 40).

2. The vertebrae are diplasiocoelous (16/0). This state is also found in Buergeria and in the outgroup but reverses to state 16/1 in Rhacophorus (Figure 29).

3. The anterior end of the frontoparietal is wider than its posterior end, and the parietosquamosal arch is absent (19/1). This character state reverses in $P$. dugritei (Figure 21).

The majority of the species in these three genera are large foam-nesting tree frogs. Therefore, this foam-nesting behavior plus related morphological structures may be a strong synapomorphy for this clade.

\section{Chiromantis}

All three species of this genus were used in the analysis. This genus is part of more inclusive clades as discussed above and so possesses the character states mentioned for those clades except where stated differently here. In addition, this genus, as the most basal taxon of the (Chiromantis (Polypedates, Rhacophorus)) clade, can be distinguished from the other two members by a combination of the following synapomorphic character states:

1. The most anterior slip of the $\mathrm{m}$. petrohyoideus posterior inserts on the membrana thyroideus (7/1). This character state also supports a clade within Rhacophorus (Figure 47).

2. The digital pad is pear-shaped and surrounded distally and laterally by a ventromarginal groove (33/3). This character state is a reversal to an earlier condition in the rhacophorid clade, being present in Buergeria and Mantidactylus OTUs (Figure 19). 
Liem distinguishes this genus by a combination of the following characters: arch-shaped anterior horn of the hyoid (considered a symplesiomorph in this analysis); reduced squamosal plate; and opposable fingers (not in analysis).

The clade of Polypedates and Rhacophorus

Three character states support these two genera as sister taxa.

1. The alary process of the hyoid is club- shaped (12/0) in $P$. dennysi, or the base is extremely broad (12/2) in remaining OTUs, which also supports the genus Philautus and which reverses to state 1 in P. macrotis (Figure 48).

2. The anterior horn of the hyoid is absent (13/1) in all OTUs of this clade (except $R$. everetti), but is also absent in Boophis tephraeomystax and Nyctixalus pictus (Figure 34).

3. A Y-shaped terminal phalanx (27/3) strongly supports this node in that it is present in all OTUs of this clade (except $R$. gauni and $R$. zamboangensis where it reverses to state 2) exclusive of all other OTUs within Rhacophoridae (Figure 24).

\section{Polypedates}

This genus of approximately 12 species was represented by the species $P$. dennysi, $P$. dugritei, $P$. leucomystax, $P$. macrotis, $P$. maculatus, $P$. omeimontis, and $P$. otilophus in the analysis. This genus may be paraphyletic in relation to Rhacophorus in that $P$. dugritei and $P$. omeimontis form a clade with members of the genus Rhacophorus, and in that $P$. dennysi is basal to the Rhacophorus and Polypedates clades (Figure 13). Recent molecular data also support the arrangement of $P$. dugritei and $P$. omeimontis with Rhacophorus (Yang and Lin, 1997). Therefore, the more exclusive clade of $P$. leucomystax, $P$. macrotis, $P$. maculatus, and $P$. otilophus will represent the genus Polypedates, which can be distinguished from Rhacophorus by a combination of the following synapomorphic character states:

1. The $\mathrm{m}$. extensor radialis accessorius lateralis inserts on the distal tendon of the $\mathrm{m}$. extensor radialis superficialis (3/0). This state is a reversal from the earlier state (3/1) that distinguishes the more inclusive (Chiromantis, Polypedates, Rhacophorus) clade (Figure 40).

2. The anterior end of the frontoparietal is wider than the posterior end, the parietosquamosal arch ranges from short (19/2), to long (19/3) in $P$. maculatus, to being a wide plate reaching to the outermost edge of the squamosal (19/4) in $P$. otilophus. This order of states is unique to Polypedates and thus strongly supports this clade (Figure 21).

Other species of Polypedates scored by Liem are $P$. colletti, $P$. cruciger, and $P$. eques. Because, $P$. cruciger has the same states as $P$. maculatus, it was omitted so as not to inflate the number of most parsimonious trees, but it is considered a member of this 
genus. When $P$. colletti and $P$. eques were added to the analysis separately or together they nested within Polypedates, but also caused $P$. dugritei and $P$. omeimontis to fall out and form a polytomy within the (Polypedates, Rhacophorus) clade. When $P$. dugritei and $P$. omeimontis were removed from the analysis, Polypedates, with $P$. colletti and $P$. eques, formed a sister group relationship with Rhacophorus. Also, $P$. eques contains both synapomorphic states (3/0 and 19/2) for Polypedates as listed above, whereas $P$. colletti has state $19 / 2$, although state $3 / 0$ reverses to $3 / 1$ in this species.

\section{Rhacophorus}

This genus of approximately 60 species is represented by the species $R$. bimaculatus (bipunctatus), $R$. everetti, $R$. javanus, $R$. gauni, $R$. moltrechti, $R$. dulitensis, $R$. nigropalmatus, and $R$. zamboangensis, and will also include the species $P$. dugritei and $P$. omeimontis as basal taxa in the analysis. This genus can be distinguished from Polypedates by the following characters:

1. The vertebrae are procoelous (16/1). This character state is a reversal within the (Chiromantis, Polypedates, Rhacophorus) clade but is scored as being present by Liem in all OTUs of the Rhacophorus clade in this analysis except $R$. nigropalmatus (Figure $\underline{29)}$.

2. A distinctly fan-shaped $\mathrm{m}$. dentomentalis; and a continuous $\mathrm{m}$. submaxillaris ventralis with $\mathrm{m}$. submaxillaris (6/1); and the insertion of the most anterior slip of the $\mathrm{m}$. petrohyoideus posterior on the membrana thyroideus (7/1) all support a more exclusive clade of just the eight species in the analysis formerly in the genus Rhacophorus (Figure 28 and Figure 47).

Liem also considered Rhacophorus and Polypedates to be sister taxa and distinguished between them by the following characters: the parieto-squamosal arch of the frontoparietal is present and usually short in most species of Polypedates but is absent in Rhacophorus; the vertebral column is diplasiocoelous in Polypedates but procoelous in Rhacophorus; the m. extensor radialis accessorius lateralis is moderately large, and originate along the lateral side of the humerus, distal to the crista ventralis in Polypedates, but is usually narrow, and originate near the crista ventralis of the humerus in Rhacophorus (these first three characters also were distinguishers between the two genera as stated above); vomerine teeth are always present in Polypedates and usually present in Rhacophorus; the m. extensor brevis superficialis of the first digit is present in most species of Polypedates but is absent in most species of Rhacophorus; the $\mathrm{m}$. cutaneous pectoris is thick and muscular in Polypedates but is thin, with only a few layers of muscle fibers in Rhacophorus; the dermal tarsal or anal fold is absent in Polypedates (except $P$. eques) but is present in many species of Rhacophorus; the dermal fold along the forearm and tarsus is absent or forms only a dermal fringe in Polypedates but is extensive in many species of Rhacophorus; and the color is usually dull, grayish with various dark markings in Polypedates but is usually bright green or brownish in Rhacophorus (the last five characters were not in the analysis). It 
is interesting that $P$. dugritei and $P$. omeimontis (which formed a clade with the Rhacophorus species) have a green dorsum, but the other members of the Polypedates clade do not. A closer relationship of these two species with members of Rhacophorus was also suggested by Matsui and Wu (1994) based on acoustic characteristics and by Yang and Lin (1997) based on molecular data (as discussed above).

Of the 13 species of Rhacophorus scored by Liem, $R$. appendiculatus, $R$. harrissoni, $R$. microtympanum, $R$. pardalis, $R$. reinwardti, and $R$. rufipes were not used in the analysis. Rhacophorus pardalis, $R$. reinwardti, and $R$. rufipes have the same character states as $R$. dulitensis so were not included to avoid inflating the number of most parsimonious trees. They are instead considered within the Rhacophorus clade. When $R$. harrissoni was added to the analysis it nested within the (Polypedates, Rhacophorus) clade but collapsed all Rhacophorus species to a polytomy with the Polypedates clade. Two of the synapomorphic character states above for Rhacophorus (16/1 and 6/1) are different for R. harrissoni.

When $R$. appendiculatus was added to the analysis, it collapsed the clades for Chirixalus, Chiromantis, Polypedates, and Rhacophorus to a polytomy. When $R$. microtympanum was added, it pulled $R$. everetti from the Rhacophorus clade to form a clade outside of the (Chirixalus (Chiromantis (Rhacophorus, Polypedates))) clade, of which Chiromantis, Polypedates, and Rhacophorus collapsed to a polytomy. As stated earlier, Liem was suspicious that $R$. appendiculatus, $R$. everetti, and $R$. microtympanum may not be in the genus Rhacophorus. Perhaps because he scored the anterior horn of the hyoid as being present (state 13/0) in these three species, whereas it is absent (state 13/1) in all other species of Rhacophorus in the analysis, and, although the Wolffian duct is considered convoluted (state 30/1) in species of Rhacophorus, he determined that it is simple (state 30/0) in these three species.

Dubois (1986) did not consider the species within Polypedates to be different enough from those within Rhacophorus based on Liem's discussion (above) to be grouped into the genus Polypedates, and therefore placed Polypedates in synonomy with Rhacophorus. Duellman (1993) did not recognize this synonomy because of the results of Channing's analysis in which Rhacophorus and Polypedates were not sister groups. Yet, the results here suggest that Polypedates and Rhacophorus do form a clade exclusive of other rhacophorid taxa and that a reanalysis of the distinguishing characters given above should be performed on the species in these genera.

Areas of Concern

From this review, we have determined that a number of errors in the identification of character states as well as errors in data entry may have occurred in both Liem's and Channing's studies. In addition to what is stated above, there are also the following:

1. In Aglyptodactylus and Mantidactylus, Liem states that the "ventral column [is] diplasiocoelous and moderately long" (pg. 87 of Liem, 1970) though all OTUs are 
scored as procoelous (16/1). Blommers-Schlosser (1993) has found that state $16 / 0$ is present in Aglyptodactylus and some Mantidactylus species but state 16/1 is present in other Mantidactylus species, Mantella, and Boophis.

2. Liem scored Boophis tephraeomystax as not having an anterior horn of the hyoid (13/1; Appendix 3 of Liem, 1970). Yet he scored the anterior horn of the hyoid as having two processes for this species (14/1). This was not caught by Channing, who also gave this species and thus the genus the same character states (Table 2 of Channing, 1989). We examined specimens of $B$. tephraeomystax (CAS 156905, 156906) and confirm the finding of Blommers-Schlosser (1993) in that it has an anterior horn of the hyoid consisting of one process (Figure 49) so would be scored with the states 13/0 and 14/2.

3. Channing excluded characters 30 and 36 from the data matrix without discussion. But character 30 may be an important character at the node that groups Chirixalus, Chiromantis, Polypedates, and Rhacophorus, while character state $36 / 4$ supports a major clade in hyperoliids.

4. Liem scored the third carpal bone as being free in Aglyptodactylus and Mantidactylus (28/0), but this state is not seen in the specimens of Mantidactylus (CAS) we examined (M. betsileanus, CAS 156772, 156777, 156835, 156846; M. ulcerosus, CAS 63950; Figure 50) which is consistent with the finding of Blommers-Schlosser (1993), who also found state 28/1 to be present in Aglyptodactylus.

5. Liem also scored the second tarsal bone as being free in Boophis, but this state is not seen in the specimens of $B$. tephraeomystax (CAS 156905, 156906) we examined (Figure 51), which is again consistent with the finding of Blommers-Schlosser (1993). Liem also scored the second tarsal bone as being fused in Mantidactylus and Aglyptodactylus, which is inconsistent with his Table 1 and text (pg. 87 of Liem, 1970). Blommers-Schlosser (1993) has found state 29/0 (free second tarsal bone) to be present in Mantidactylus but not in Aglyptodactylus.

6. Liem's description of the direction of change for character 3 (m. extensor radialis accessorius lateralis) differs from his ordering diagram in that he states "since the shift of the insertion of the $\mathrm{m}$. extensor radialis accessorius lateralis from the distal portion of the $\mathrm{m}$. extensor radialis superficialis to the radio-ulna involves more complex evolutionary change than the reduction in size of the muscle, states 1 and 2 are considered as a separate lineage, and both are derived from state 0 ", but the diagram shows state 2 as being derived from state 1 (pg. 19 of Liem, 1970).

In addition to the above, Blommers-Schlosser (1993) claims other inconsistencies and errors in character identification by Liem.

Current Status 
Since Liem's paper in 1970, there have been a number of studies besides Channing's dealing with the phylogenetic systematics and taxonomy of genera Liem considered part of the rhacophorid clade. For example, Jiang et al. (1987), with species from China and based on morphological characters, produced a phylogenetic hypothesis that is congruent with the analysis above (Figure 52) in that Polypedates and Rhacophorus are sister taxa, and form a clade with Chirixalus; whereas Philautus is basal to this clade and Buergeria is the most basal genus. Nishioka et al. (1987), with species from Japan and based on allozyme data, also produced a hypothesis in which Buergeria was again the most basal genus, and Polypedates and Rhacophorus were sister lineages. Also, Yang and Lin (1997) and Wilkinson (1997) looked at phylogenetic relationships of taxa from Japan and China using DNA sequence data and came to similar conclusions, in that Rhacophorus and Polypedates were sister taxa followed by Chirixalus and then Buergeria. Also, in Yang and Lin's (1997) study, members of Chirixalus ( $C$. eiffingeri and $C$. idiootocus) formed a clade with Philautus ( $P$. cavirostris). However, all of these studies were limited to the species of those regions (China and Japan) and did not include other rhacophorid genera. Wilkinson (1997) and Yang and Lin (1997) used only one outgroup taxon in their analyses, while Jiang et al. (1987) and Nishioka et al. (1987) used no outgroup taxa.

Richards and Moore (1998) also performed a phylogenetic analysis on rhacophorids using DNA sequence data but included Asian, African, and Malagasy taxa, with Aglyptodactylus sister to Boophis, and Mantidactylus sister to Mantella. As for the Asian taxa, Buergeria was most basal; Philautus formed a clade with Chirixalus; and Chiromantis, Polypedates, and Rhacophorus formed a clade, with Chiromantis and Polypedates being sister taxa (Figure 53). Again, as with Yang and Lin (1997), C. eiffingeri and C. idiootocus were used to represent Chirixalus, though they may not be members of that genus (as discussed above). Also, Nyctixalus and Theloderma were not included in the analysis.

Ford and Cannatella (1993), in a review of higher order taxonomy of batrachians, rightly contended that the monophyly of the (Hyperoliidae, Rhacophoridae) clade as given above is suspect because of a lack of outgroup taxa in Liem's original analysis to polarize the characters. Laurent (1986) and Blommers-Schlosser and Blanc (1993) regarded the sister taxon to hyperoliids to be the arthroleptids. Laurent (1986) based this on a cartilaginous metasternum, vertical pupil, a free third carpal, and a free second tarsal being similar between arthroleptid and hyperoliid species. Blommers-Schlosser and Blanc (1993) also considered rhacophorids to be a subfamily of ranids, and considered the genera Mantella and Mantidactylus to make up the ranid subfamily Mantellinae.

Blommers-Schlosser (1993), in an investigation of the phylogenetic relationship of mantelline ranids with other "firmisternal" frogs based on morphological characters, concluded that Arthroleptidae, Hyperoliidae, Mantellinae, Ranidae, and Rhacophoridae formed a clade separate from other firmisternal frogs. Also, Hyperoliidae formed a clade with Arthroleptidae based on the synapomorphy of the thyrohyals abutting onto cartilaginous stalks of the hyoid plate. Whereas, Mantellinae, Ranidae, and 
Rhacophoridae formed a clade based on the following three synapomorphies: the third carpal is fused with the fourth and fifth, and second centrale; the metasternum has a bony style; and the $\mathrm{m}$. cutaneous pectoris is present. The mantelline genera of Mantella and Mantidactylus were sister taxa based on the synapomorphy of an abbreviated mating contact, and the (Mantella, Mantidactylus) clade was sister to the Rhacophoridae based on the synapomorphy of intercalary elements. However, she delegated mantelline ranids and rhacophorids as separate subfamilies of Ranidae because of their nested position within a ranid clade, and because the mantelline genera were basal to the rhacophorid genera.

Emerson et al. (in press), in analyzing the relationships of major ranoid taxa based on both morphological and molecular data, also concluded that hyperoliids formed a clade with arthroleptids (with the genus Leptopelis as the most basal taxon), and that this clade was separated from rhacophorids, which formed a clade with ranids.

Also, Mantella and Mantidactylus, which were sister taxa in their analysis, either formed a clade with an (Aglyptodactylus, Boophis) clade and this clade was sister to the remaining rhacophorids, or the (Mantella, Mantidactylus) clade was basal to all rhacophorid taxa, as concluded by Blommers-Schlosser (1993). When only the 10 morphological characters from the Emerson et al. (in press) study were analyzed, all rhacophorid taxa of Liem (including Mantella and Mantidactylus) were identical in character state. Furthermore, the (arthroleptid, hyperoliid) clade was supported by the presence of a cartilaginous stalk on the thyohyal, whereas the (ranid, rhacophorid) clade was supported by the presence of the $\mathrm{m}$. cutaneous pectoris and the presence of a bony metasternum. The presence of intercalary elements appears to be independently derived in hyperoliids and rhacophorids (Figure 54).

Glaw et al. (1998) considered Aglyptodactylus to be more closely related to the genus Tomopterna based on morphological characters, and thus transferred Aglyptodactylus out of rhacophorids and into the subfamily Raninae. Yet, the exclusion of other ranid and rhacophorid taxa in their analysis, except for representative species of the Madagascar genera Boophis, Mantella, and Mantidactylus, makes the conclusions premature because in Richards and Moore's (1998) phylogenetic hypothesis the species Tomopterna labrosa was part of a clade that included Aglyptodactylus madagascariensis and two species of Boophis, and a clade with Mantidactylus grandidieri and Mantella sp. was sister to this.

\section{CONCLUSION}

The aims of this paper were first to determine how different results can derive from apparently the same data set, and second, to determine if the characters originally scored by Liem are phylogenetically informative. In addressing the first aim, we discovered that methodological differences resulted in the different phylogenetic hypotheses between Liem's, Channing's, and our analyses. In particular, though both Channing's and our analyses used the same parsimony method, because he restricted his OTUs to one representative species per genus from the available species scored, the results differed. Other studies addressing the issue of taxon sampling have 
concluded that increasing the number of taxa in an analysis may better resolve phylogenetic relationships, especially if the added taxa are selected to ensure coverage of the group of interest and to break up long branches (Hillis, 1998 and references therein). We believe that Channing was trying both to ensure coverage of the relevant groups and to minimize long branches by choosing species with the most plesiomorphic character states from within each genus. But, by doing so, possible synapomorphies for the genus (if the genus is a monophyletic group) were not apparent, as the selected species may not actually be members of the clade. This was particularly evident in the support of the genus Rhacophorus as a monophyletic group and the support of its sister group relationship with Polypedates instead of Chirixalus. Also, Channing made scoring errors that resulted in false relationships (i.e..., Nyctixalus and Theloderma as sister taxa). The results presented by Channing have been used without question in making taxonomic statements for this family (Duellman, 1993). We believe therefore that it is important to address these results and if possible correct or improve upon them.

In addressing the second aim, we discovered that most genera with multiple species could be defined by synapomorphic character states, and more inclusive clades also had strong support. For example, the genus Philautus was strongly supported as a monophyletic group by multiple characters, and all Asian genera except for Buergeria formed a monophyletic group based on strong support. Therefore, the original characters scored by Liem apparently hold up to phylogenetic scrutiny, but support for some clades is weak. Buergeria is tentatively the basal genus of this family based on morphological characters (though this is not supported by molecular characters as discussed above). As with both Liem's and Channing's analyses, Aglyptodactylus forms a clade with Mantidactylus. But Nyctixalus is sister to Philautus not Theloderma, and Chiromantis forms a clade with a (Polypedates, Rhacophorus) clade not Philautus as Channing had hypothesized.

In this light, we believe that the results here only serve as a baseline for future needed work. The characters for the genera and major clades should be tested with other species, and if they also hold up, then they should be used to assign new species to the appropriate genus. However, these characters should be carefully surveyed for each species in any additional analysis, because some were mis-scored (as discussed above). Also, the transformation series as hypothesized by Liem should be reevaluated, as some of them are difficult to interpret in an evolutionary sense and are based on little evidence outside of Liem's opinion. An analysis that includes both morphological characters (in addition to those scored by Liem) along with molecular characters is currently being undertaken by the authors. In this respect, the phylogenetic position of Theloderma is being reviewed because it was scored with many missing characters in Liem's original analysis, and along with Nyctixalus it was not included in any molecular data set. Whether Chirixalus eiffingeri and its closely related species $C$. idiootocus belong to the genus Chirixalus is also being tested, because inclusion of $C$. eiffingeri within Chirixalus has been questioned based on morphological characters, yet it has been used in molecular analyses as the representative of Chirixalus where it has been the sister group to Philautus (Yang and Lin, 1997; Richards and Moore, 1998). 
Finally, the addition of more inclusive outgroup taxa is required to determine whether the Malagasy genera of Aglyptodactylus, Boophis, Mantidactylus, and Mantella form a monophyletic group with the African and Asian genera

of Buergeria, Chirixalus, Chiromantis, Nyctixalus, Philautus, Polypedates, Rhacophorus, and Theloderma, as is suggested by Richards and Moore (1998), or whether some of these genera are part of other ranoid clades as suggested by Glaw et al. (1998). These outgroup taxa should include a majority of the ranid taxa, and representative ranoid taxa (arthroleptids, dendrobatids, Hemisus, hyperoliids, and microhylids), plus taxa that are considered outside of the ranoid clade such as bufonoid taxa (i.e., bufonids, hylids, and leptodactylids).

We thank J. Slowinski, R. Brown, D. Cannatella, and two anonymous reviewers for their valuable comments on the manuscript (the conclusions of this paper reflect only the views of the authors). This work was partially supported by a Tilton Postdoctoral Fellowship to JAW.

\section{LITERATURE CITED}

BERRY, P. Y.

1975. The Amphibian Fauna of Peninsular Malaysia. Tropical Press, Kuala Lumpur, Malaysia.

BLOMMERS-SCHLOSSER, R. M. A.

1993. Systematic relationships of the Mantellinae Laurent 1946 (Anura Ranoidea). Ethology Ecology \& Evolution 5:199-218.

AND C. P. BLANC.

1993. Amphibiens (deuxieme partie). Faune de Madagascar, Paris. 75:385-530.

BOURRET, R.

1942. Les Batraciens De L'Indochine. Memoires de L'Institut Oceanographique de

L'Indochine. Gouvernement

General de L'Indochine. Hanoi.

BROWN, W. C., A. C. ALCALA, AND R. M. BROWN.

1998. Taxonomic status of Cornufer worcesteri Stejneger. J. Herpetology 32:131-133.

CHANNING, A.

1989. A re-evaluation of the phylogeny of Old World treefrogs. South African Journal of Zoology 24:116-131.

DE QUEIROZ, K. AND J. GAUTHIER.

1992. Phylogenetic taxonomy. Annual Review of Ecology and Systematics 23:449-480.

DREWES, R. C.

1984. A phylogenetic analysis of the Hyperoliidae (Anura): Tree frogs of Africa, 
Madagascar, and the Seychelles

Islands. Occasional Papers of the California Academy of Sciences 139:1-70.

DUBOIS, A.

1981. Liste des genres et sous-genres nominaux de Ranoidea (Amphibiens Anoures) du monde, avec identification

de leurs especes-types: Consequences nomenclaturales. Monit. Zool. Ital. N.S., Suppl., 15:225-284.

1986. Miscellanea taxinomica batrachologica (I). Alytes 5:7-95.

DUELLMAN, W. E.

1993. Amphibian Species of the World: Additions and Corrections. The University of Kansas, Lawrence, Kansas.

AND L. TRUEB.

1986. Biology of Amphibians. McGraw-Hill Book Co., New York.

DUTTA, S. K. AND K. MANAMENDRA-ARACHCHI.

1996. The Amphibian Species of Sri Lanka. Wildlife Heritage Trust of Sri Lanka, Colombo, Sri Lanka.

EMERSON, S. B., C. RICHARDS, R. C. DREWES, AND K. M. KJER.

1999. On the relationships among ranoid frogs: A review of the evidence. Herpetologica in press

FORD, L. S. AND D. C. CANNATELLA.

1993. The major clades of frogs. Herpetological Monographs 7:94-117.

FROST, D. R.

1985. Amphibian Species of the World. Allen Press and the Assoc. of Systematic Collections, Lawrence, Kansas.

GLAW, F. AND M. VENCES.

1992. A Field Guide to the Amphibians and Reptiles of Madagascar. Moos-Druck, Leverkusen, Germany.

GLAW, F., M. VENCES, AND W. BOHME.

1998. Systematic revision of the genus Aglyptodactylus Boulenger, 1919 (Amphibia: Ranidae), and analysis of its phylogenetic relationships to other Madagascan ranid genera (Tomopterna, Boophis, Mantidactylus, and Mantella).

J. Zoological Systematics and Evolutionary Research 36:17-37.

HILLIS, D. R.

1998. Taxonomic sampling, phylogenetic accuracy, and investigator bias. Systematic Biology 47:3-8. 
INGER, R. F.

1954. Systematics and zoogeography of Philippine Amphibia. Fieldiana: Zoology 33:181-531.

1966. The systematics and zoogeography of the Amphibia of Borneo. Fieldiana:

Zoology 52:1-402.

JIANG, S., S. HU, AND E. ZHAO.

1987. The approach of the phylogenetic relationships and the supraspecific

classification of 14 Chinese species of

treefrogs (Rhacophoridae). Acta Herpetologica Sinica 6:43-47.

KIRTISINGHE, P.

1957. The Amphibia of Ceylon. Colombo, Ceylon.

LAURENT, R. F.

1986. The systematic position of the genus Afrixalus Laurent (Hyperoliidae). Alytes 5:16.

LIEM, S. S.

1970. The morphology, systematics, and evolution of the Old World treefrogs

(Rhacophoridae and Hyperoliidae).

Fieldiana Zoology 57:1-145.

LIU, C.-C. AND S.-C. HU.

Tailess Salientia in China. Kolsuo-Chuppan [Scientific Press], Peking.

LUE, K.-Y. AND J.-S. LAI.

1990. The Amphibians of Taiwan. Taiwan Provincial Department of Education, Nantou.

MADDISON, W. P. AND D. R. MADDISON.

1992. MacClade, Version 3.04. Sinauer Associates, Inc. Publishers. Sunderland Massachusetts.

MAEDA, N. AND M. MATSUI.

1990. Frogs and Toads of Japan. Bun-Ichi Sogo Shuppan Co., Tokyo.

MATSUI, M. AND G.-F. WU.

1994. Acoustic characteristics of treefrogs from Sichuan, China, with comments on systematic relationship of

Polypedates and Rhacophorus (Anura, Rhacophoridae). Zoological Science 11:485-

490.

NAKAMURA, K. AND S. UENO.

1963. Japanese Reptiles and Amphibians in Colour. Hoikusha Publishing Co., Ltd., Osaka, Japan. 
NISHIOKA, M., M. SUMIDA, S. OHTA, AND H. SUZUKI.

1987. Speciation of three allied genera, Buergeria, Rhacophorus, and Polypedates, elucidated by the method of

electrophoretic analyses. Scientific Report of the Laboratory for Amphibian Biology, Hiroshima Univ. 9:53-96.

RICHARDS, C. M. AND W. S. MOORE.

1998. A molecular phylogenetic study of the old world treefrog family Rhacophoridae.

Herpetological Journal 8:41-46.

SWOFFORD, D. L.

1999. PAUP*. Phylogenetic Analysis Using Parsimony ( ${ }^{*}$ and other methods), Version 4. Sinauer Associates, Sunderland Massachusetts.

TAYLOR, E. H.

1962. The amphibian fauna of Thailand. University of Kansas Science Bulletin 43:265599.

WILKINSON, J. A.

1997. Historical biogeography of rhacophorid frogs from Japan, the Ryukyu Archipelago, and Taiwan inferred from a phylogenetic perspective. Ph.D. Dissertation, Texas Tech University, Lubbock, Texas.

YANG, Y.-J. AND Y.-S. LIN.

1997. Molecular phylogenetics and biogeography of the genus Rhacophorus in Taiwan. American Society of Ichthyologists and Herpetologists, 77th Annual Meeting, Seattle Washington, 1997.

Submitted: 1 November 1998 